\title{
Why does the hemolytic activity of silica predict its pro-inflammatory activity?
}

\author{
Cristina Pavan ${ }^{1}$, Virginie Rabolli², Maura Tomatis ${ }^{1 *}$, Bice Fubini ${ }^{1}$ and Dominique Lison ${ }^{2^{*}}$
}

\begin{abstract}
Background: The hemolytic activity of inhaled particles such as silica has been widely investigated in the past and represents a usual toxicological endpoint to characterize particle reactivity despite the fact that red blood cells (RBCs) are not involved in the pathogenesis of pulmonary inflammation or fibrosis caused by some inhaled particles. The inflammatory process induced by silica starts with the activation of the inflammasome, which leads to the release of mature IL-1 $\beta$. One of the upstream mechanisms causing activation of the inflammasome is the labilization of the phagolysosomal membrane after particle phagocytosis. Considering RBC lysis as a model of membrane damage, we evaluated the relationship between hemolytic activity and inflammasome-dependent release of IL-1 $\beta$ for a panel of selected silica particles, in search of the toxicological significance of the hemolytic activity of an inhaled particle.
\end{abstract}

Methods: Well-characterized silica particles, including four quartz samples and a vitreous silica, with different surface properties and hemolytic potential were tested for their capacity to induce inflammasome-dependent release of IL-1 $\beta$ in LPS-primed primary murine peritoneal macrophages by ELISA and Western blot analysis. The mechanisms of IL-1 $\beta$ maturation and release were clarified by using ASC-deficient cells and inhibitors of phagocytosis and cathepsin B.

Results: The silica samples induced dose-dependent hemolysis and IL-1 $\beta$ release of different amplitudes. A significant correlation between IL-1 $\beta$ release and hemolytic activity was evidenced $(r=0.827)$ by linear regression analysis. IL-1 $\beta$ release was completely abolished in ASC-deficient cells and reduced by inhibitors, confirming the involvement of the inflammasome and the requirement of phagocytosis and cathepsin B for activation.

Conclusions: The same physico-chemical properties of silica particles which are relevant for the lysis of the RBC membrane also appear implicated in the labilization of the phagolysosome, leading to inflammasome activation and release of the pro-inflammatory cytokine IL-1 $\beta$. These findings strengthen the relevance of the hemolysis assay to predict the pro-inflammatory activity of silica dusts.

Keywords: Red blood cells, Hemolysis, Inflammasome, Silica, Quartz, IL-1ß, Lysosomal damage, Phagolysosome, Alveolar macrophages, Membrane interaction

\section{Background}

Even if the pathogenicity of silica particles is known from ancient times, it remains one of the most puzzling issues of particle toxicology [1]. The mechanism of action of crystalline silica dusts was deeply investigated in the 50', when the incidence of silicosis caused by exposure to respirable dusts was high in numerous occupational settings;

\footnotetext{
*Correspondence: m.tomatis@unito.it; Dominique.lison@uclouvain.be 'Department of Chemistry, "G. Scansetti" Interdepartmental Center for Studies on Asbestos and Other Toxic Particulates, University of Torino, Via P. Giuria 7, 10125 Turin, Italy

${ }^{2}$ Louvain Center for Toxicology and Applied Pharmacology (LTAP), Université catholique de Louvain, Avenue E. Mounier 52 - bte B1.52.12, 1200 Brussels, Belgium
}

\section{Biomed Central}

then revisited by many investigators by the end of the $90^{\prime}$ because of the progressive awareness that, under some circumstances, crystalline silica is also a human carcinogen [2]. The potential toxicity of silica is today back to the stage with the growing interest in nanotechnology and the use of amorphous silica nanoparticles (NPs) for several applications, including biomedicine. A large number of studies highlighted the role of lung cells (e.g. macrophages, epithelial cells) in the development of silica-induced diseases, but the physico-chemical properties of silica particles determining these cellular responses and the overall mechanism of toxicity remains only partially solved. Indeed, both in vivo and in vitro studies reflect a great 
variety of cellular responses to silica, not only among various forms (for instance, crystalline silica is known to cause chronic effects such as silicosis and cancer while amorphous silica produces only transient inflammation) and polymorphs of silica, but also among quartz specimens of similar origin $[3,4]$. Differences found in the carcinogenic activity in humans [5,6] and in experimental studies [7] led to the awareness of a "variability" of silica hazard, ascribed to the multiplicity of the physico-chemical properties of silica involved and to differences in the surface state of apparently similar silica samples [8].

Although red blood cells (RBCs) do not play any role in the inflammatory or fibrotic responses induced by silica, the RBC membrane has been traditionally regarded as a simple and convenient experimental model [9] and the hemolysis test was largely used in the past to assess the surface reactivity of silica and many more mineral species [9-11]. More recently, a number of studies have re-considered the hemolytic activity of inorganic particles, especially of silica [12-18]. In spite of conflicting opinions on the consistency between in vitro and in vivo studies due to a plethora of measurable endpoints for each toxicological manifestation [11,19], the hemolytic activity has been considered one of the best predictors of in vivo inflammation for metal oxide nanoparticles $[14,18]$. In particular, a correlation between the ability of some quartz dusts to cause in vivo inflammation and to induce hemolysis in vitro was found, supporting the contention that lung inflammogenicity is driven by some surface properties of quartz [12,13]. However, a link between hemolytic activity and cellular responses, e.g. cytotoxicity, has not always been found because of the complexity of the physico-chemical determinants imparting toxicity to a silica particle. Each property may be differently involved in the various steps of the pathogenic response to silica [8] and could differently affect each cell type [16]. All these contrasting findings leave open the question about the toxicological significance of assessing the hemolytic activity of an inhaled particle. Silica particles are highly hemolytic and - as with other silica-related biological responses - the hemolytic activity also varies dramatically from one to the other silica specimens in a rather complex way. In a previous study we have used a large set of silica samples, differing in most of the physico-chemical properties claimed to be related to cellular responses to silica, in order to identify which was the major feature determining RBC lysis. Hemolytic activity varied from absent to very high. From a detailed analysis and comparison, it was concluded that the surface distribution of silanols, silanolate and siloxane was the primary factor causing hemolysis [20]. Taking advantage of the availability of this panel of well-characterized silica samples largely differing in their hemolytic potential, we have here attempted to find a relationship between silica hemolytic activity and the reported biological events involved in the progression towards silicosis and cancer [6].

The inflammatory reaction is one of the first steps involved in the lung pathogenesis induced by silica. Recent reports revealed that both crystalline [21-23] and amorphous silica [24-26], trigger inflammation through the activation of the inflammasome protein complex which regulates the maturation and release of cytokines of the IL-1 family [27]. The Nalp3 receptor (also known as NLRP3), member of a family of cytoplasmic immune receptors (NLRs), is involved in this reaction. When activated, Nalp3 can recruit the adaptor apoptosis-associated speck-like protein (ASC) inducing the activation of the proteolytic enzyme caspase-1. The latter initiates cell death and controls the cleavage and secretion of the pro-inflammatory cytokine interleukin IL-1 $\beta[28,29]$ whose persistent overproduction has been linked to silicosis [30]. The upstream biochemical mechanism of Nalp3 inflammasome activation is still partially unclear [31,32], but two pathways, probably interconnected, have been proposed [33]. The first one involves ROS generation, that could activate directly or indirectly Nalp3 [21,22,34,35], the second entails lysosome damage leading to release the lysosomal content, including hydrolytic enzymes such as cathepsin B, into the cytosol. This hypothesis is based on the observation that both phagosomal destabilization induced by particles [23,24,36,37] and pharmacological disruption of lysosomes [23] lead to the activation of the Nalp3 inflammasome. Early research in the past century had already revealed the ability of alveolar macrophages to incorporate insoluble particles into a phagolysosome, thus initiating cell death pathways following disruption of the phagolysosome [38-40].

Since damage to the phagolysosome is a crucial event in triggering the inflammatory pathway caused by silica particles, we hypothesized here that direct interaction of the lysosomal membrane with specific functionalities on silica particle surface (e.g. silanol groups, silanolates, siloxanes) plays a role in lysosomal destabilization similarly to the way they cause the lysis of RBCs. The aim of the present study is to investigate the pro-inflammatory response by measuring inflammasome activation by a panel of silica samples selected for their diverse RBC lysis activity, and to evaluate the relationship between their capacity to activate the inflammasome and their hemolytic activity. In order to span a large interval in hemolytic potential, we have chosen two very active silica samples, two with intermediate activity and an inactive one. Release of IL-1 $\beta$ was assessed in primary murine peritoneal macrophages. To verify the role of the inflammasome in IL-1 $\beta$ release, experiments were performed in macrophages from ASC-deficient mice versus wild-type. To clarify the mechanism leading to inflammasome 
activation, the experiments were repeated in the presence of an inhibitor of phagocytosis and of the lysosomal enzyme cathepsin B.

\section{Results}

Physico-chemical properties and hemolytic potential of the silica samples investigated

The study was conducted with the following five samples:

1. the commercial microcrystalline $\alpha$-quartz Min-U-Sil $5(\mathrm{Q} z-1)$;

2. Min-U-Sil 5 heated at $800^{\circ} \mathrm{C}(\mathrm{Q} z-2)$;

3. a pure quartz obtained by grinding a crystal from Madagascar $(Q z-3)$;

4. a pure ground quartz etched with hydrofluoric acid $(Q z-4)$;

5. a vitreous silica obtained by grinding a very pure silica glass $(V S)$.

The physico-chemical properties of the silica particles are reported in Table 1. All the samples considered were obtained by grinding. Their morphology is thus irregular, with acute spikes and edges, typical of ground material. Except vitreous silica (VS), they all have a crystalline structure. They were selected for the present investigation because of their similar size and surface area but different hemolytic activity and silanol distribution. We have also shown that the hemolytic activity of these samples is unrelated to their potential to release free radicals [20], and Qz-3, Qz-4 and VS exhibited a limited potential to generate particle-derived free radicals [41], which was appropriate to minimize other factors than membranolytic activity that may activate the inflammasome.

We previously reported the hemolytic potential of Qz$1, \mathrm{Qz}-2$ and VS [20] $(\mathrm{Q} z-1 \cong V S>Q z-2)$. The RBC lysis activity of Qz-3 (originating from a different batch than that previously tested in [20]) and Qz-4 (not tested before) was examined here (Figure 1) and compared in Table 1 with the hemolytic activity of the other three silica samples. Since RBC membranolysis is a surface-driven process, doses were expressed per surface area unit (Table 1). Both silica samples showed a dose-dependent hemolytic activity from 6.25 up to $200 \mathrm{~cm}^{2} / \mathrm{ml}$. The hemolytic potential of Qz-4 was higher than that of Qz-3 at any of the doses investigated.

\section{Varying cytotoxic responses of murine macrophages}

Cytotoxic activity was determined in preliminary experiments over a range of concentrations (Additional file 1: Figure S1) in order to avoid the use of cytotoxic doses and irrelevant release of immature pro-IL-1 $\beta$ in the culture supernatant in subsequent experiments. Primary murine peritoneal macrophages were primed with LPS [22] and incubated $6 \mathrm{~h}$ with LPS-free silica particles. Figure 2 shows the cell viability determined by WST-1 assay at the concentration of $20 \mathrm{~cm}^{2} / \mathrm{ml}$ of silica sample. VS was the most cytotoxic, followed by the commercial quartz Qz-1 and Qz-2. Qz-3 was not statistically different compared to the control, while Qz-4 showed an intermediate cytotoxic activity. Only VS was already cytotoxic at the lowest dose of $10 \mathrm{~cm}^{2} / \mathrm{ml}$. Qz-2 was less cytotoxic than Qz-1 at the highest dose of $40 \mathrm{~cm}^{2} / \mathrm{ml}$, while Qz-3 was fully inactive at all the doses investigated (Additional file 1: Figure S1). Based on these results, we selected a low $\left(20 \mathrm{~cm}^{2} / \mathrm{ml}\right)$ and a moderately cytotoxic dose $\left(40 \mathrm{~cm}^{2} / \mathrm{ml}\right)$ as appropriate to evaluate silica-induced mature IL-1 $\beta$ release.

\section{Varying activation of IL- $1 \beta$ release}

The effects caused by the set of silica particles on IL-1 $\beta$ release from primary murine peritoneal macrophages are reported in Figure 3. After $6 \mathrm{~h}$ incubation with the particles at the concentration of $20 \mathrm{~cm}^{2} / \mathrm{ml}$, culture supernatants were collected to determine the levels of IL-1 $\beta$

Table 1 Main physico-chemical characteristics and hemolytic activity of the selected silica samples

\begin{tabular}{|c|c|c|c|c|c|c|c|c|}
\hline \multirow[t]{2}{*}{$\overline{\text { Silica }}$} & \multirow[t]{2}{*}{$\mathrm{SSA}\left(\mathrm{m}^{2} / \mathrm{g}\right)^{\mathrm{b}}$} & \multicolumn{2}{|c|}{ Particle size $(\mu \mathrm{m})^{c}$} & \multirow{2}{*}{$\begin{array}{l}\text { Major metal impurities } \\
\text { (\% oxides) }\end{array}$} & \multicolumn{2}{|c|}{ Free radical generation $^{d}$} & \multirow{2}{*}{$\begin{array}{l}\% \text { Hemolysis } \\
\text { (at } 100 \mathrm{~cm}^{2} / \mathrm{ml} \text { ) }\end{array}$} & \multirow[t]{2}{*}{ Ref. } \\
\hline & & $\begin{array}{l}\text { Average } \\
\text { diameter }\end{array}$ & $90 \%$ percentile & & $\mathrm{HO}$ & $\mathrm{COO}^{--}$ & & \\
\hline$\overline{Q z-1}$ & 5.2 & $1.7 \pm 0.7$ & 2.6 & Al 1.4, Fe 0.06 & ++ & +++ & $++^{a}$ & {$[20,47]$} \\
\hline Qz-2 & 5.2 & $1.4 \pm 0.6$ & 2.1 & $\mathrm{Nd}$ & $\mathrm{Nd}$ & $\mathrm{Nd}$ & $+^{\mathrm{a}}$ & {$[20]$} \\
\hline Qz-3 & 6.1 & $1.7 \pm 1.8$ & 2.8 & Absent & ++ & absent & absent & {$[41]$} \\
\hline Qz-4 & 6.1 & $1.5 \pm 1.0$ & 2.5 & $\mathrm{Nd}$ & $\mathrm{Nd}$ & $\mathrm{Nd}$ & $t^{\mathrm{a}}$ & - \\
\hline VS & 3.1 & $1.6 \pm 1.2$ & 2.7 & Absent & + & absent & $++^{a}$ & {$[20,40]$} \\
\hline
\end{tabular}

${ }^{a}+, 10-20 \% ;++, 35-45 \%$ hemolysis.

${ }^{\text {b }}$ Specific surface area (SSA) evaluated by BET (Brunauer, Emmet and Teller method).

${ }^{c}$ Determined by flow particle image analysis which measures the average diameter expressed as circle equivalent (CE) diameter \pm SD. The $90 \%$ percentile is the value of the CE diameter below which $90 \%$ of observations falls.

${ }^{d}$ Measured by electron paramagnetic resonance (EPR) spectroscopy and using DMPO as a trapping agent. Hydrogen peroxide or sodium formate were used as target molecules to generate respectively hydroxyl $\left(\mathrm{HO}^{\circ}\right)$ or carboxyl $\left(\mathrm{COO}^{-}\right)$radicals.

$\mathrm{Nd}$ : Not determined. 


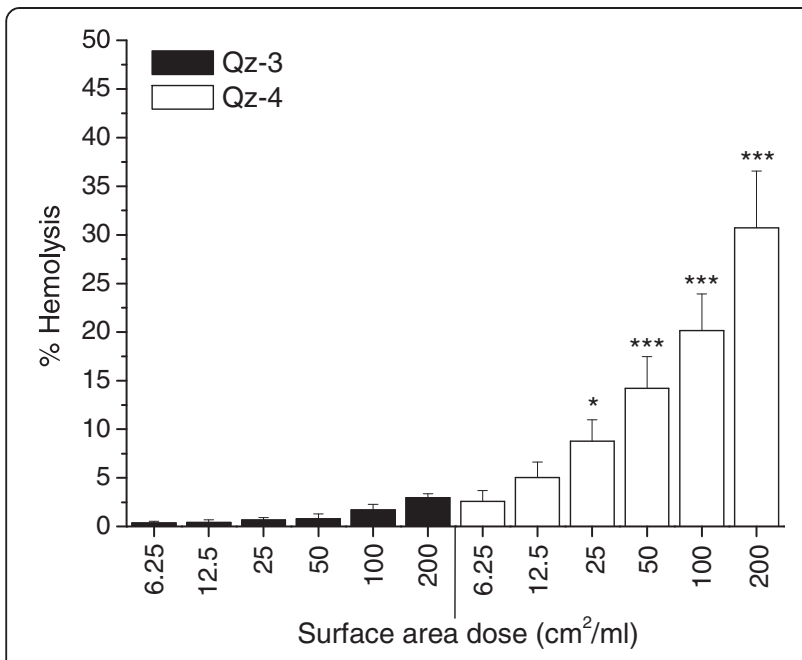

Figure 1 Hemolytic activity of Qz-3 (pure quartz) and Qz-4 (pure quartz etched with HF). Qz-3 and Qz-4 were incubated at increasing concentrations expressed as surface area doses $\left(\mathrm{cm}^{2} / \mathrm{ml}\right)$ in the presence of human red blood cells. Values are mean \pm SD from five independent experiments. ${ }^{*} p<0.05$ and ${ }^{* *} p<0.001$ vs control not exposed to silica particles.

produced. A large variation in the capacity to activate IL-1 $\beta$ release from one to the other silica particle was detected. Significant levels of IL- $1 \beta$ were induced by all the silica samples, with the exception of Qz-3. The latter was also tested at the highest dose of $40 \mathrm{~cm}^{2} / \mathrm{ml}$ and

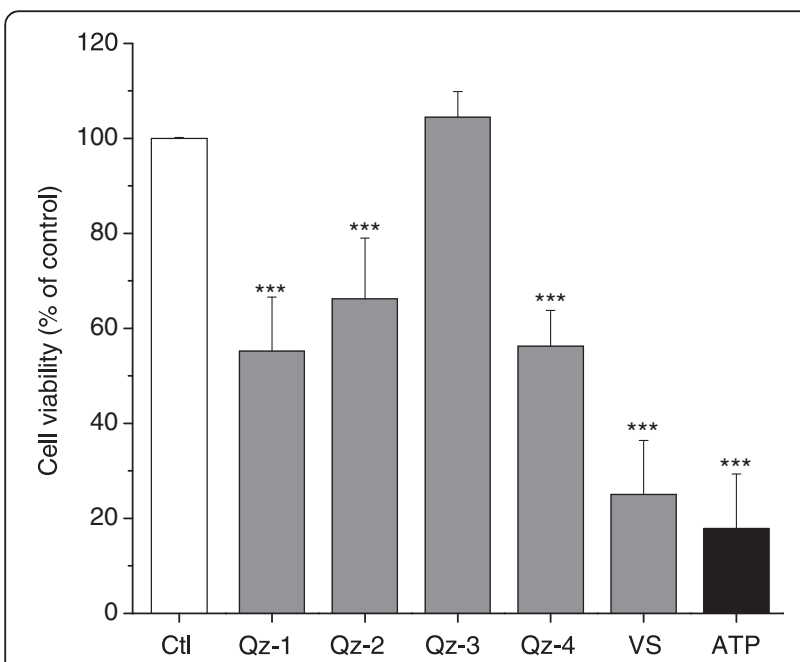

Figure 2 Cytotoxic activity of different silica particles in primary murine macrophages. LPS-primed primary murine macrophages were incubated with $20 \mathrm{~cm}^{2} / \mathrm{ml}$ of silica for $6 \mathrm{~h}$ and then evaluated for cell viability by means of the WST-1 assay. The silica samples included a commercial quartz (Qz-1), the same quartz heated at $800^{\circ} \mathrm{C}(\mathrm{Qz}-2)$, a vitreous silica (VS), a pure quartz (Qz-3) and the pure quartz etched with HF (Qz-4). ATP (5 mM) was used as positive control. Results are expressed as percentage of the control (macrophages not exposed to silica particles $-\mathrm{Ct}$ ). Values are mean \pm SD from at least three independent experiments. ${ }^{* *} \mathrm{p}<0.001$ vs control not exposed to silica particles.

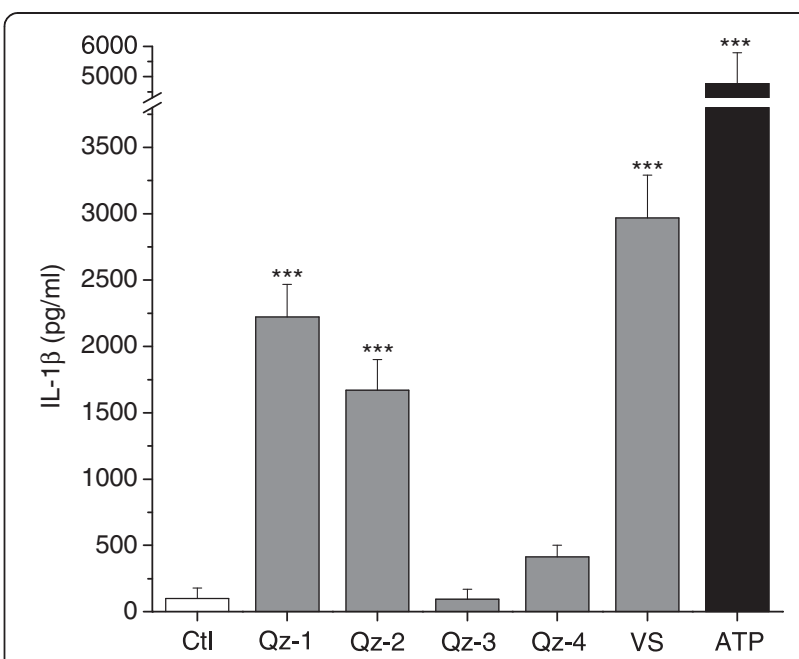

Figure $3 \mathrm{IL}-1 \beta$ release from primary murine macrophages induced by different silica particles. LPS-primed primary murine macrophages were incubated with $20 \mathrm{~cm}^{2} / \mathrm{ml}$ of silica for $6 \mathrm{~h}$ and then evaluated for $\mathrm{IL}-1 \beta$ production $(\mathrm{pg} / \mathrm{ml})$ in culture supernatants by ELISA. The silica samples were a commercial quartz (Qz-1), the same heated at $800^{\circ} \mathrm{C}(\mathrm{Qz}-2)$, a vitreous silica (VS), a pure quartz (Qz-3) and the pure quartz etched with HF (Qz-4). ATP (5 mM) was used as positive control. Values are mean $\pm \mathrm{SD}$ including data from three independent experiments. ${ }^{* *} \mathrm{p}<0.001$ vs control not exposed to silica particles.

remained inactive (Additional file 1: Figure S2). Qz-1 and Qz-2 induced high level of IL- $1 \beta$ secretion (increased at $40 \mathrm{~cm}^{2} / \mathrm{ml}$ ), while IL-1 $\beta$ release was definitely high for VS at both concentrations. Qz-4 induced a low release of IL-1 $\beta$, more than Qz-3 but less than all the other silica samples. On the basis of these results, subsequent experiments on IL- $1 \beta$ release were carried out at $20 \mathrm{~cm}^{2} / \mathrm{ml}$.

Release of mature IL-1 $\beta$ is inflammasome-dependent and requires phagocytosis and lysosomal rupture

To discriminate between mature IL- $1 \beta$ released into the supernatant after inflammasome activation and immature pro-IL- $1 \beta$ potentially due to silica cytotoxicity, we performed a Western blot analysis to separate the two proteins on the basis of their different molecular weight. LPS-primed macrophages were incubated for $6 \mathrm{~h}$ with $20 \mathrm{~cm}^{2} / \mathrm{ml}$ of silica or with ATP $(5 \mathrm{mM})$ used as positive control. As shown in Figure 4A, significant differences in the expression levels of mature IL- $1 \beta$ among cells treated with various types of silica were observed. VS showed the highest amount of mature IL- $1 \beta$, even more than the ATP positive control. Qz-1 induced a lower amount of mature IL- $1 \beta$ compared to VS, whereas IL-1 $\beta$ could not be detected for Qz-2 and Qz-3. Detection of mature/pro-IL-1 $\beta$ in the supernatant or cell extract not exposed to silica $(\mathrm{Ctl})$ showed that priming with LPS was effective because only the pro-IL-1 $\beta$ form was present in cell extract, and no release of mature IL-1 $\beta$ 

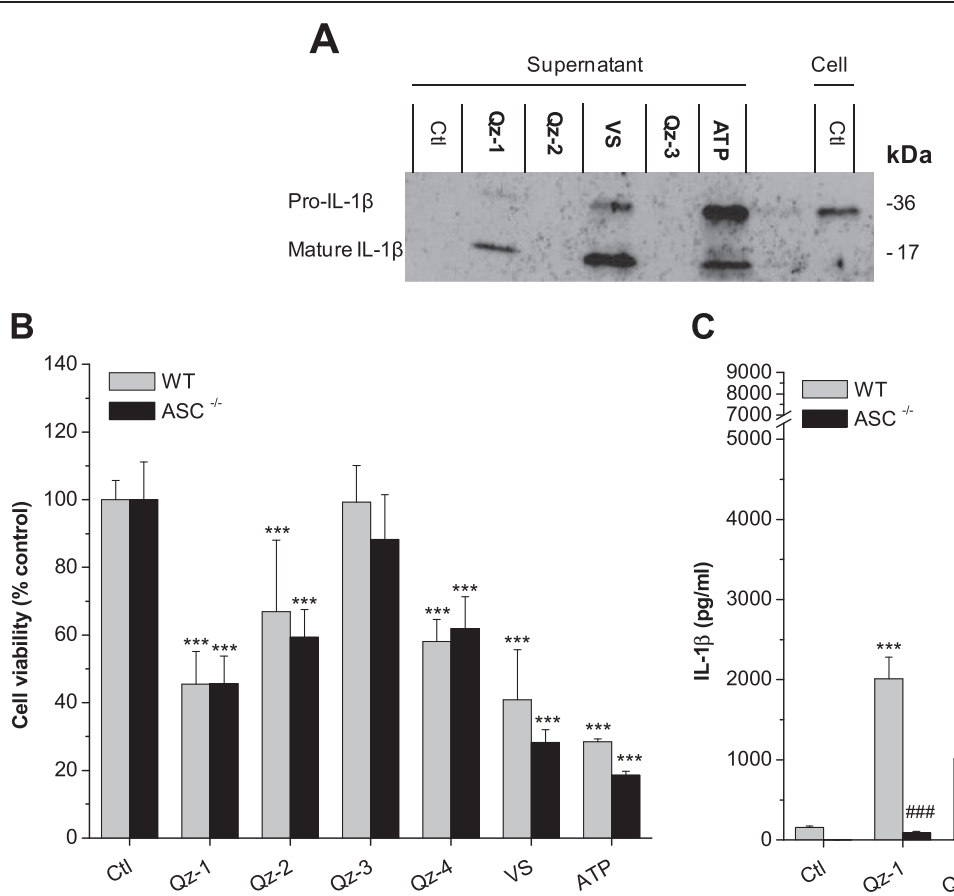

C
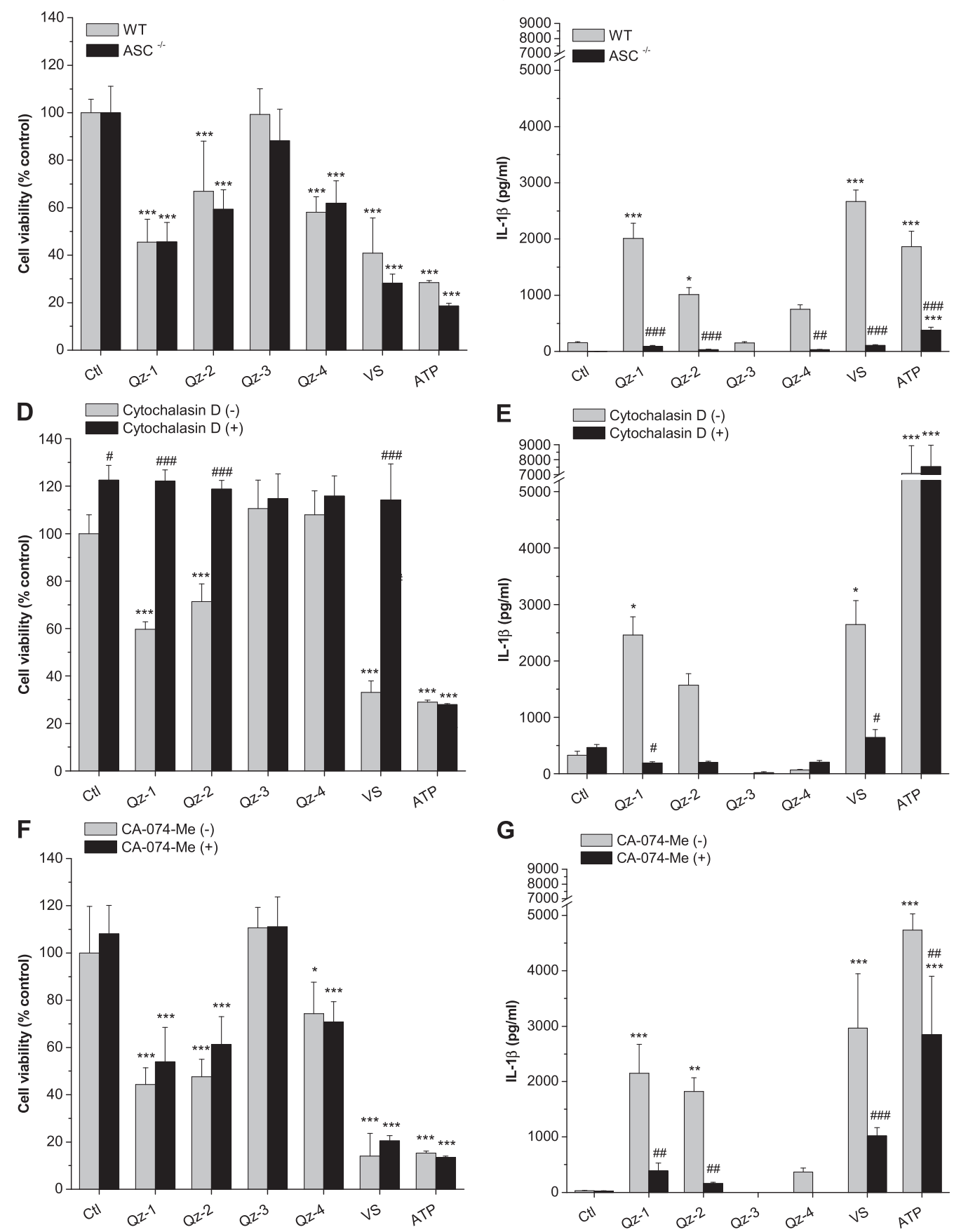

Figure 4 (See legend on next page.) 
(See figure on previous page.)

Figure 4 Involvement of the inflammasome, phagocytosis and cathepsin B in inducing the release of mature IL-1 $\beta$ by different silica particles. LPS-primed primary murine macrophages were incubated with silica at equal surface dose $\left(20 \mathrm{~cm}^{2} / \mathrm{ml}\right)$ and with ATP $(5 \mathrm{mM})$ as positive control. Culture supernatants were collected after $6 \mathrm{~h}$ ( $1 \mathrm{~h}$ for ATP) and cell viability by WST-1 (B, D, F) and IL-1 $\beta$ release $(\mathrm{pg} / \mathrm{ml})$ by ELISA (C, E, G) were measured. (A) A representative Western blot analysis conducted on culture supernatants or cell extracts to detect pro-IL-1 $\beta(17 \mathrm{kDa})$ or mature IL-1 $\beta$ (36 kDa) is shown. (B, C) WT mice and mice deficient in the adaptor molecule ASC $\left(\mathrm{ASC}^{-/-}\right)$are compared. Determinations were performed in six replicates (B) or quadruplicate $\mathbf{C}$ ) in a single experiment and expressed as the mean \pm SD. Cells pre-treated for $1 \mathrm{~h}$ with cytochalasin $\mathrm{D}(5 \mu \mathrm{M})(\mathbf{D}, \mathbf{E})$ or CA-074-Me $(10 \mu \mathrm{M})(\mathbf{F}, \mathbf{G})$ are compared to untreated cells. Determinations were performed in quadruplicate and expressed as the mean \pm SD. Data from one representative experiment out of two $\mathbf{( D ,} \mathbf{E})$ or one single experiment $(\mathbf{F}, \mathbf{G})$ are depicted. ${ }^{*} \mathrm{p}<0.05,{ }^{* *} p<0.01$ and ${ }^{* * *} p<0.001$ vs control not exposed to silica particles in each group; ${ }^{\#} \mathrm{p}<0.05$, ${ }^{\# \#} \mathrm{p}<0.01$ and ${ }^{\# \# \#} \mathrm{p}<0.001$ WT vs $\mathrm{ASC}^{-1-}$ or non-treated vs treated with inhibitors, for each sample.

was found in the supernatant. These results are consistent with the data obtained by ELISA. In order to evaluate the involvement of inflammasome in the release of IL-1 $\beta$ by several silica types and to confirm the mechanism leading to its activation, ASC-deficient cells, a phagocytosis inhibitor and an inhibitor of cathepsin B were used. Peritoneal macrophages from mice knockout for the apoptosis-associated speck-like protein $\left(\mathrm{ASC}^{-1-}\right)$, which is one of the three main components of the inflammasome complex, were compared with macrophages from wild type mice (WT, C57BL/6). No significant difference in cytotoxic activity between WT and $\mathrm{ASC}^{-/-}$macrophages was found (Figure $4 \mathrm{~B}$ ), indicating that silica-induced cytotoxicity is independent from ASC, as reported by Cassel et al. for Nalp3 [22]. LPSprimed $\mathrm{ASC}^{-/-}$macrophages displayed an evident defect in their ability to induce IL-1 $\beta$ compared with macrophages from WT (Figure 4C). The relative order of cytotoxicity and IL-1 $\beta$ production of the silica samples reflected the one already reported in Figures 2 and 3.

To inhibit phagocytosis, macrophages were pre-treated with cytochalasin D, an inhibitor of actin filament polymerization. Cytotoxicity was clearly reduced in the presence of cytochalasin D (Figure 4D). Cytochalasin $\mathrm{D}$ also reduced silica-induced IL-1 $\beta$ secretion (Figure 4E), whereas neither cytotoxicity nor IL-1 $\beta$ release were affected in cells challenged with ATP, a non-particulate inflammasome activator that does not require cellular phagocytosis. To investigate whether cathepsin B, an hydrolytic enzyme released into the cytosol after lysosomal destabilization, was involved in silicainduced IL-1 $\beta$ production [23], cells were pre-treated with a membrane-permeable cathepsin B-specific inhibitor (CA-074-Me). Cell toxicity was not affected by the inhibitor (Figure $4 \mathrm{~F}$ ), while IL- $1 \beta$ response was markedly reduced for all the silicas (Figure 4G). Overall, the present results indicate that cytotoxicity is induced after internalization of the particles, and that particle uptake and the ASC protein are required for IL-1 $\beta$ processing in macrophages for all the silica samples tested. Moreover, silica-induced IL- $1 \beta$ production is triggered by active cathepsin $\mathrm{B}$ present into the cytoplasm, suggesting that lysosomal damage, leakage of lysosomal active enzymes into the cytosol and finally activation of the inflammasome occurred $[22,23,36]$.

The release of IL-1 $\beta$ induced by the different silica samples correlates with their hemolytic activity

IL- $1 \beta$ levels induced by the different types of silica were reported as a function of their hemolytic activity in Figure 5. A linear regression analysis between the hemolytic activity and IL- $1 \beta$ release from primary murine macrophages indicates a clear correlation $(r=0.827)$ for the panel of silica particles here investigated.

\section{Discussion}

The physico-chemical properties of silica may play different and specific roles in initiating the cascade of events resulting in the inflammatory and fibrotic responses involved in silicosis. A tentative association between the surface properties of silica particles and the sequence of events leading to the pathogenic condition after in vivo inhalation has been proposed by Fubini [8]. Among the various surface functionalities present on silica, some are related to particle-membrane interactions, such as the response observed in the hemolytic assay, and others to the activation of lung cells (e.g. alveolar macrophages and polymorphonucleated cells) which secrete inflammatory mediators and lead to development of inflammation and fibrosis. It is still not clear however, how these properties and the biological responses are interconnected.

All the silica samples examined here, except the nonhemolytic quartz (Qz-3), induced a pro-inflammatory effect promoting secretion of IL-1 $\beta$. This response was highly varying among the set of selected silica particles, which reveals that variations are mostly due to the surface properties of the particles as sizes and surface areas were very similar. Min-U-Sil 5 quartz heated under drastic conditions (Qz-2), with the aim to reduce surface hydrophilicity by silanol condensation $[42,43]$, was less active for IL-1 $\beta$ release than non-treated Min-U-Sil 5 (Qz-1). The pure quartz etched with hydrofluoric acid (Qz-4) to dissolve the external amorphous layer and remove surface defects [44] was more active than the pure Qz-3 in inducing a pro-inflammatory response. Vitreous 


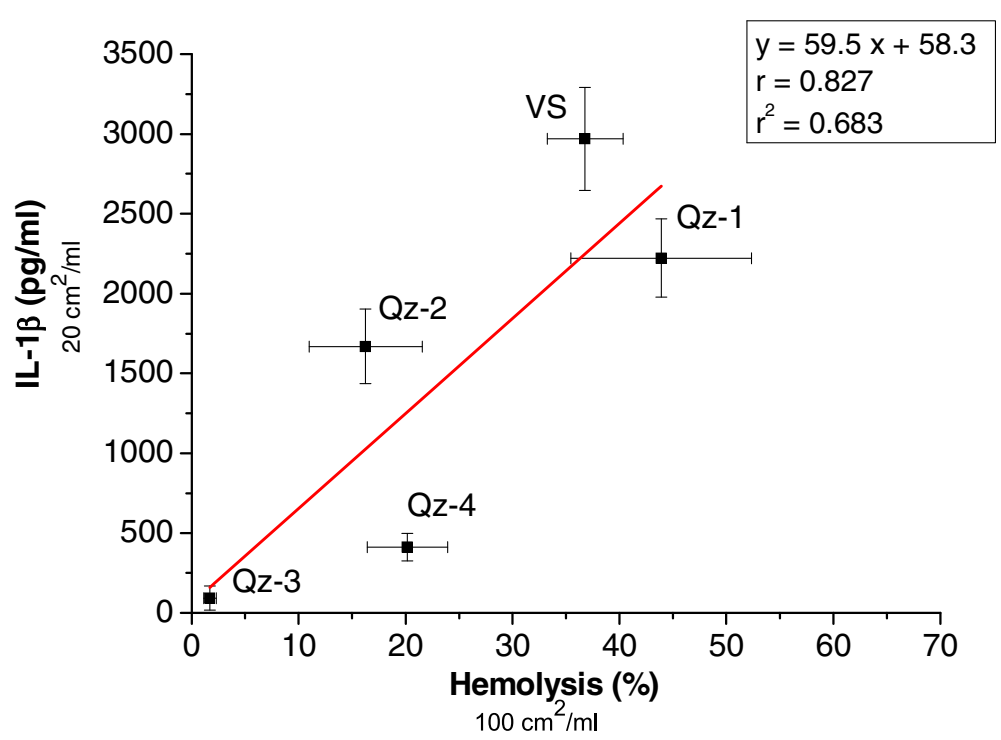

Figure 5 Correlation between hemolytic activity and IL-1 $\beta$ release caused by silica particles. Percent of hemolysis at silica concentration of $100 \mathrm{~cm}^{2} / \mathrm{ml}$ and release of $\mathrm{IL}-1 \beta(\mathrm{pg} / \mathrm{ml})$ from murine primary macrophages at silica concentration of $20 \mathrm{~cm}^{2} / \mathrm{ml}$ were compared by linear regression analysis. Values for hemolysis (\%) are means of three to five independent experiments, while values for IL-1 $\beta(\mathrm{pg} / \mathrm{mL})$ are means $\pm S D$ including data from three independent experiments. Parametric linear regression analysis (Pearson) was applied.

silica (VS), with physico-chemical features very similar to a quartz dust except crystallinity [41], was even more inflammogenic than all quartz. This last point indicates that crystallinity is not required to produce an IL-1 $\beta$ response to silica, as previously reported by Sandberg and co-workers [24] and in agreement with Gazzano et al. [45], although amorphous silica is known to produce only transient inflammation compared to crystalline silica $[7,46]$.

The generation of particle-derived free radicals in cell free environment, which is unrelated to hemolysis [20], appears not to play a role in IL- $1 \beta$ secretion for the present set of silica samples. Indeed, VS is less active in 'OH release than Qz-1 and Qz-3. Moreover, neither VS nor Qz-3 are able to catalyze carbon-centered radicals, contrary to Qz-1 [41,47].

We showed that three factors were involved in the IL$1 \beta$ release upon exposure to our silica samples, the ASC protein, phagocytosis and active lysosomal protease cathepsin $\mathrm{B}$, ascertaining the implication of the inflammasome. Our results also suggest that lysosomal damage is required to activate the inflammasome. The ability of pristine and modified silica particles to induce the release of IL- $1 \beta$ in macrophages strictly paralleled their hemolytic activity (Figure 5), which depends on silica physico-chemical properties that could be modified by surface treatments. The correlation between the hemolytic potential of the silica particles and their IL- $1 \beta$ response suggests that the physico-chemical properties relevant for RBC membranolysis may also be implicated in the labilization of the phagolysosome and could mediate inflammasome activation. As previously reported [20], silanol distribution plays a central role in silica hemolytic activity. We could then speculate that the external RBC membrane and the internal phagolysosomal membrane could both have a structure sensitive to a specific silanol arrangement. Many decades ago the group of Wallingford et al. [48] noted that the physico-chemical reactivity of the $\mathrm{RBC}$ membrane may resemble the lysosomal one, based on the fact that agents which produce RBC lysis (Vitamin A, lysolecithin, weak acids, polyene antibiotics, and sodium urate crystals) also damage lysosomes. This seemed to be more evident for silica when both hemolysis and phagolysosome rupture were inhibited by the polymer PVPNO which is a strong hydrogen acceptor [38]. PVNO was recently reported by Peeters and co-workers [49] to reduce the level of Nalp3 inflammasome activation by quartz. Recent papers $[50,51]$ reported a reduced in vitro and in vivo inflammasome activation following surface functionalization of multiwalled carbon nanotubes with the $\mathrm{COOH}$ acidic group, which is largely deprotonated in physiological solution. A decrease in the inflammasomedependent IL-1 $\beta$ production and in endosomal rupture was also evidenced by Morishige et al. [36] for amorphous silica particles after their modification with different functional groups (- $\left.\mathrm{COOH},-\mathrm{NH}_{2},-\mathrm{SO}_{3} \mathrm{H},-\mathrm{CHO}\right)$.

The peculiarity of silica is its strong hydrogen-bond potential compared to other inorganic compounds. This is mostly due to the intermediate electronegativity of silicon which falls between non metals oxides, acting as Brønsted acids, and metal oxides turning into hydroxo compounds with basic properties when hydrated. Through silanols, 
silica acts as a hydrogen donor in the formation of hydrogen-bond with hydrogen acceptors largely present at the biomembrane surface, including phosphate ester groups of phospholipids or secondary amide (peptide) groups of proteins [52].

\section{Conclusions}

In this study we considered a panel of silica particles for investigating the connection between the hemolytic activity and the release of the pro-inflammatory cytokine IL-1 $\beta$ from macrophages. A strong correlation between hemolytic activity and pro-inflammatory potential was observed, suggesting that the same silica physico-chemical properties which are relevant in $\mathrm{RBC}$ membrane rupture may also be implicated in the labilization of the phagolysosome, leading to inflammasome activation. The present data strengthen the toxicological relevance of the hemolysis assay to predict the pro-inflammatory activity of silica dusts.

\section{Methods}

Silica samples

The five silica samples used, whose main characteristics are reported in Table 1, were: $(Q z-1)$ the commercial microcrystalline $\alpha$-quartz Min-U-Sil 5, largely used in studies of experimental silicosis and lung cancer [5], purchased from U.S. Silica Co. (Berkeley Springs, WV); $(Q z-2)$ the Min-U-Sil 5 quartz heated in vacuum at $800^{\circ} \mathrm{C}$ for $2 \mathrm{~h}$ to reduce surface hydrophilicity [43,44,53]; $(Q z-3)$ obtained by grinding a very pure quartz crystal from Madagascar in a planetary ball mill (Retsch S100, GmbH, Haan, Germany) for $3 \mathrm{~h}$ (70 rpm), then in the mixer mill (Retsch MM200) for $9 \mathrm{~h}(27 \mathrm{~Hz})$. The grinding process was performed in an agate jar to keep silica free from impurities. This sample, contrary to what was found with other batches [20] of the same material, was inert in hemolysis. $(Q z-4)$ obtained again from a pure quartz crystal from Madagascar following the same grinding procedure of $\mathrm{Qz}-3$, and then treating $100 \mathrm{mg}$ with a solution $0.1 \mathrm{M}$ of hydrofluoric acid for $10 \mathrm{~min}$. The dust was centrifuged ( $2500 \mathrm{rpm}$ for $20 \mathrm{~min}$ ), washed four times with distilled water and dried at $100^{\circ} \mathrm{C}$ for $3 \mathrm{~h}$. The treatment was conducted with the aim to smoothen up surface defects and irregularities [44]. (VS) a vitreous silica with size distribution and surface area close to typical commercial quartz dusts, obtained by grinding a very pure silica glass (Suprasil) produced for optical applications in a ball mill (agate jar) for 3 hours (70 rpm).

\section{Chemical reagents}

Dulbecco's modified Eagle medium (DMEM), fetal bovine serum (FBS), phosphate buffered saline (PBS) and penicillin-streptomycin $(10,000 \mathrm{U}$ and $10,000 \mathrm{mg} / \mathrm{ml})$ were obtained from Invitrogen (Bleiswijk, Netherlands). The
WST-1 reagent was purchased from Roche Applied Science (Vilvoorde, Belgium). $\mathrm{NaCl} 0,9 \%$ was obtained from B. Braun Medical (Diegem, Belgium), Triton X-100 from Flucka (Buchs, Switzerland), the cathepsin B inhibitor CA-074-Me from Bachem (Switzerland). Methanol, dimethyl sulfoxide (DMSO), Tris buffered saline, Tween 20, lipopolysaccharide (LPS), cytochalasin D, ATP and chloroform were purchased from Sigma-Aldrich, 2mercaptoethanol, Laemmli Sample Buffer from Bio-Rad (Hercules, USA) and hydrofluoric acid (HF) from Merck (Darmstadt, Germany).

\section{Particle characterization}

Surface area measurements were performed by means of the BET method based on $\mathrm{N}_{2}$ adsorption at $-196^{\circ} \mathrm{C}$ (Quantasorb, Quantachrome Instrument).

Particle size was obtained by using a flow particle image analyzer (Sysmex FPIA-3000, Malvern Instruments, UK; detection range: $0.8-300 \mu \mathrm{m}$ ). This instrument measures the diameter of the circle having the same projected area as the particle image detected. Measurements were carried out on sample suspensions at a concentration of $1 \mathrm{mg} / \mathrm{ml}$ in saline. Each sample was run at least four times with objective lens at 20× magnification in high power field (HPF) mode. The four analyses were then pooled to obtain the final mean value of size \pm standard deviation (SD).

\section{Hemolysis of human RBCs}

RBCs were separated from fresh human blood of a healthy volunteer donor not receiving any pharmacological treatment. The protocol for hemolysis measurement refers to $\mathrm{Lu}$ et al. [14], with minor modifications given in Pavan et al. [20]. Hemolytic activity of silica particles was evaluated on the basis of surface dose $\left(\mathrm{cm}^{2}\right.$ silica/ml).

\section{Primary macrophage cell isolation and culture}

Peritoneal macrophages were selected for the present study as they produce large amounts of IL-1 $\beta$ and can be easily obtained from genetically deficient animals. Macrophages were obtained by peritoneal lavage with $10 \mathrm{ml} \mathrm{NaCl} 0.9 \%$ of male $\mathrm{C} 57 \mathrm{BL} / 6$ or $\mathrm{ASC}^{-/-}$mice in a C57BL/ 6 background sacrificed with sodium pentobarbital. Mice were housed in positive pressure air-conditioned units $\left(25^{\circ} \mathrm{C}, 50 \%\right.$ relative humidity) on a $12 \mathrm{~h}$ light/dark cycle. ASC-deficient mice were obtained from the Transgenose Institute (Orléans, France).

Peritoneal lavage fluid was centrifuged for $10 \mathrm{~min}$ at $1250 \mathrm{rpm}$ (Centrifuge 5804, Eppendorf, Hamburg, Germany), the supernatant was removed and cells $(2 \times$ $10^{5}$ cells/well) were seeded in 96-well plates using DMEM (1 g/l D-glucose) medium supplemented with 10\% FBS, penicillin $(100 \mathrm{U} / \mathrm{ml})$ and streptomycin $(100 \mu \mathrm{g} / \mathrm{ml})$. Cells were incubated $4 \mathrm{~h}$ at $37^{\circ} \mathrm{C}$ in a $5 \% \mathrm{CO}_{2}$-supplemented atmosphere. 


\section{Cell priming and particle exposure}

Macrophages were rinsed twice with cell culture medium and primed with LPS $(100 \mathrm{ng} / \mathrm{ml})$ for $18 \mathrm{~h}\left(37^{\circ} \mathrm{C}, 5 \% \mathrm{CO}_{2}\right)$.

Silica particles were heated at $200^{\circ} \mathrm{C}$ for $2 \mathrm{~h}$ just prior to suspension in order to sterilize them and inactivate any trace of endotoxin. Silica suspensions were prepared at the final concentration of $40 \mathrm{~cm}^{2}$ silica/ml in serum free DMEM. Suspensions were sonicated in a bath during $2 \mathrm{~min}$. Serial dilutions were performed just before use to 20 and $10 \mathrm{~cm}^{2} / \mathrm{ml}$. Silica suspensions or serum free DMEM (control) were distributed $(200 \mu \mathrm{l} /$ well $)$ in six replicates in cell culture plates and incubated for $6 \mathrm{~h}$. ATP ( $5 \mathrm{mM}$ ) (positive control) was added to parallel wells $1 \mathrm{~h}$ before the end of the incubation. In the experiments with inhibitors, LPS-primed macrophages were pre-incubated for $1 \mathrm{~h}$ with cytochalasin $\mathrm{D}(5 \mu \mathrm{M})$ or CA-074-Me $(10 \mu \mathrm{M})$, the latter reconstituted in DMSO (in this case the negative control was serum free DMEM added with $0,1 \% \mathrm{DMSO}$ ). At the end of the exposure period, supernatants were collected in a new plate and stored at $-20^{\circ} \mathrm{C}$ to assess IL- $1 \beta$ content, while cytotoxicity was determined on adhering cells.

\section{Cytotoxicity and Enzyme-Linked ImmunoSorbent Assay (ELISA)}

Cytotoxicity was assessed with the WST-1 assay as described previously [54]. Briefly, WST-1 is a colorimetric assay quantifying mitochondrial activity as a measure of cell viability. 10\% WST-1 reagent diluted in medium was added $(100 \mu \mathrm{l} /$ well $)$ and culture plates were incubated about $40-50 \mathrm{~min}$. Supernatants were moved to a new plate and absorbance of the formazan dye formed was measured at a wavelength of $450 \mathrm{~nm}$ and a correction wavelength of $690 \mathrm{~nm}$ by UV/vis spectrophotometry (Infinite 200, Tecan, Grödig, Austria). Results are expressed as a percentage of the negative control.

Culture supernatants were assayed for IL-1 $\beta$ using an ELISA kit for mouse IL-1 $\beta /$ IL-1 F2 (DY401, R\&D Systems, Minneapolis, USA) according to the manufacturer's instructions. This ELISA preferentially recognizes mature IL-1 $\beta$, but also the pro-IL- $1 \beta$ form although to a lesser extent.

\section{Western blotting}

Pro-IL-1 $\beta$ and mature IL- $1 \beta$ were discriminated by Western Blot. Primary macrophages were seeded at a density of $1.2 \times 10^{6}$ cells/well in a 24-well plate with supplemented DMEM. Cell priming and particle exposure were as indicated previously, except that silica particles were tested at the single concentration of $20 \mathrm{~cm}^{2} / \mathrm{ml}$. After exposure to particles, proteins in the supernatants were precipitated by adding an equal volume of methanol and 0.25 volume of chloroform. Supernatants were centrifuged for $15 \mathrm{~min}$ at $12,000 \times \mathrm{g}$
(Centrifuge 5804, Eppendorf). The upper alcoholic phase was discarded and a volume of methanol equal to the interphase containing the proteins and the lower chloroform phase was added. The mixture was centrifuged for $15 \mathrm{~min}$ at $12,000 \times$ g. Supernatant was removed, the protein pellet dried for $10-15 \mathrm{~min}$ at $55^{\circ} \mathrm{C}$ and suspended in Sample Buffer (a mixture 1:20 of 2-mercaptoethanol and Laemmli Sample Buffer respectively). Alternatively, tissue culture pellets were lysed using $300 \mu \mathrm{l}$ of Sample Buffer and, after thorough mixing, transferred to microcentrifuge tubes. Cell lysates and precipitates were stored at $-20^{\circ} \mathrm{C}$. After thawing, protein precipitates were sonicated for $5 \mathrm{~min}$ in a bath, boiled at $99^{\circ} \mathrm{C}$ for $5 \mathrm{~min}$ and centrifuged for $10 \mathrm{~min}$ at $14,000 \mathrm{rpm}$. Proteins were separated by $20 \%$ SDS-polyacrylamide gel electrophoresis (SDS-PAGE) (Mini-PROTEAN TGX 4-20\%, BioRAD Life Science, Hercules, USA). A protein ladder was also added (PageRuler Plus Prestained Protein Ladder, Fermentas, St. Leon-Rot, Germany). Proteins separated by SDS-PAGE were transferred to a nitrocellulose membrane (Hybond-C Extra, Amersham Biosciences, Piscataway, USA). Before blocking, Ponceau-staining was used to control protein levels. The membrane was blocked with $5 \%$ milk for $1 \mathrm{~h}$ at room temperature (RT) and then incubated with the primary antibody (polyclonal goat anti-mouse IL-1 $\beta$ IgG, AF-401-NA, $R \& D$ Systems, Minneapolis, USA) overnight at $4^{\circ} \mathrm{C}$ on a rotating platform. The membrane was washed three times with Tris Buffered Saline containing 0.1\% Tween 20 and incubated for $1 \mathrm{~h}$ at RT with the respective secondary horseradish peroxidase-conjugated antibody (rabbit antigoat IgG-HRP, Santa Cruz Biotechnology, Santa Cruz, USA). After washing the membrane three times with Tris Buffered Saline containing 0.1\% Tween 20 and once with Tris alone, the blot was developed using the SuperSignal West Pico or Femto chemiluminescent substrates (Thermo Scientific, Rockford, USA) according to the manufacturer's instructions.

\section{Statistical analysis}

Data are presented as mean \pm standard deviation (SD). Differences between groups were analyzed by one-way analysis of variance (ANOVA) with post hoc Tukey's pairwise comparison test. Differences with $p$ value $<0.05$ were considered statistically significant. Linear regression analysis (Pearson's coefficient) was applied in Figure 5.

\section{Additional file}

Additional file 1. Figure S1. Cytotoxic activity caused by increasing doses of different silica particles in primary murine macrophages. Figure S2. $\mathrm{IL}-1 \beta$ release from primary murine macrophages induced by increasing doses of different silica particles.

\section{Competing interests}

The authors declare that they have no competing interests. 


\section{Authors' contributions}

$\mathrm{CP}$ contributed to the experimental design, carried out the hemolysis and in vitro experiments, analyzed the experimental results and drafted the manuscript. VR participated in the coordination of the study and in the experimental work, helped in the interpretation of the results and revised the manuscript. MT contributed to the collection of silica samples, evaluation of the results and revision of the manuscript. BF participated in the experimental design, helped in analyzing the results and in drafting the manuscript. DL conceived the study, participated in its design and coordination, helped in the interpretation of the data and in writing the manuscript. All authors read and approved the final manuscript.

\section{Acknowledgements}

We gratefully acknowledge the financial support of the Erasmus Programme and the doctoral fellowship given by the Italian Workers' compensation Authority (INAIL) of Piemonte to CP.

Received: 26 September 2014 Accepted: 11 December 2014 Published online: 19 December 2014

\section{References}

1. Donaldson $\mathrm{K}$, Seaton A: A short history of the toxicology of inhaled particles. Part Fibre Toxicol 2012, 9:13.

2. International Agency for Research on Cancer (IARC): Silica and Some Silicates. In IARC Monographs on the Evaluation of Carcinogenic Risks to Humans. Vol 42. Lyon: IARC; 1987.

3. Fubini B, Fenoglio I, Ceschino R, Ghiazza M, Martra G, Tomatis M, Borm P, Schins R, Bruch J: Relationship between the state of the surface of four commercial quartz flours and their biological activity in vitro and in vivo. Int J Hyg Envir Heal 2004, 207:89-104.

4. Bruch J, Rehn S, Rehn B, Borm PJA, Fubini B: Variation of biological responses to different respirable quartz flours determined by a vector model. Int J Hyg Envir Heal 2004, 207:203-216.

5. International Agency for Research on Cancer (IARC): Silica, Some Silicates, Coal Dust and Para-Aramid Fibrils. In IARC Monographs on the Evaluation of Carcinogenic Risks to Humans. Vol 68. Lyon: IARC; 1997.

6. International Agency for Research on Cancer (IARC): A Review of Human Carcinogens: Arsenic, Metals, Fibres, and Dusts. In IARC Monographs on the Evaluation of Carcinogenic Risks to Human. Vol 100C. Lyon: IARC; 2012

7. Napierska D, Thomassen LCJ, Lison D, Martens JA, Hoet PH: The nanosilica hazard: another variable entity. Part fibre toxicol 2010, 7:39.

8. Fubini B: Surface chemistry and quartz hazard. Ann Occup Hyg 1998, 42:521-530.

9. Nolan RP, Langer AM, Harington JS, Oster G, Selikoff IJ: Quartz hemolysis as related to its surface functionalities. Environ Res 1981, 26:503-520.

10. Koshi $\mathrm{K}$, Hayashi $\mathrm{H}$, Sakabe $\mathrm{H}$ : Cell toxicity and hemolytic action of asbetos dusts. Ind Health 1968, 6:69-79.

11. Driscoll KE: The toxicology of crystalline silica studied in vitro. App/ Occup Environ Hyg 1995, 10:1118-1125.

12. Clouter A, Brown D, Höhr D, Borm P, Donaldson K: Inflammatory effects of respirable quartz collected in workplaces versus standard DQ12 quartz: particle surface correlates. Toxicol Sci 2001, 63:90-98.

13. Duffin R, Gilmour PS, Schins RPF, Clouter A, Guy K, Brown DM, MacNee W, Borm PJ, Donaldson K, Stone V: Aluminium lactate treatment of DQ12 quartz inhibits its ability to cause inflammation, chemokine expression, and nuclear factor-kappa B activation. Toxicol Appl Pharmacol 2001, 176:10-17.

14. Lu SL, Duffin R, Poland C, Daly P, Murphy F, Drost E, MacNee W, Stone V, Donaldson K: Efficacy of simple short-term in vitro assays for predicting the potential of metal oxide nanoparticles to cause pulmonary inflammation. Environ Health Perspect 2009, 117:241-247.

15. Warheit DB, Webb TR, Colvin VL, Reed KL, Sayes CM: Pulmonary bioassay studies with nanoscale and fine-quartz particles in rats: toxicity is not dependent upon particle size but on surface characteristics. Toxicol Sci 2007, 95:270-280.

16. Rabolli V, Thomassen LC, Princen C, Napierska D, Gonzalez L, Kirsch-Volders M, Hoet PH, Huaux F, Kirschhock CE, Martens JA, Lison D: Influence of size, surface area and microporosity on the in vitro cytotoxic activity of amorphous silica nanoparticles in different cell types. Nanotoxicology 2010, 4:307-318.
17. Yu T, Malugin A, Ghandehari H: Impact of silica nanoparticle design on cellular toxicity and hemolytic activity. ACS Nano 2011, 5:5717-5728.

18. Cho WS, Duffin R, Bradley M, Megson IL, MacNee W, Lee JK, Jeong J, Donaldson K: Predictive value of in vitro assays depends on the mechanism of toxicity of metal oxide nanoparticles. Part Fibre Toxicol 2013, 10:55.

19. Sayes CM, Reed KL, Warheit DB: Assessing toxicity of fine and nanoparticles: comparing in vitro measurements to in vivo pulmonary toxicity profiles. Toxicol Sci 2007, 97:163-180.

20. Pavan C, Tomatis M, Ghiazza M, Rabolli V, Bolis V, Lison D, Fubini B: In search of the chemical basis of the hemolytic potential of silicas. Chem Res Toxicol 2013, 26:1188-1198.

21. Dostert C, Pétrilli V, Van Bruggen R, Steele C, Mossman BT, Tschopp J: Innate immune activation through Nalp3 inflammasome sensing of asbestos and silica. Science 2008, 320:674-677.

22. Cassel SL, Eisenbarth SC, lyer SS, Sadler JJ, Colegio OR, Tephly LA, Carter AB, Rothman PB, Flavell RA, Sutterwala FS: The Nalp3 inflammasome is essential for the development of silicosis. Proc Natl Acad Sci U S A 2008, 105:9035-9040.

23. Hornung V, Bauernfeind F, Halle A, Samstad EO, Kono H, Rock KL, Fitzgerald KA Latz E: Silica crystals and aluminum salts activate the NALP3 inflammasome through phagosomal destabilization. Nat Immunol 2008, 9:847-856.

24. Sandberg WJ, Låg M, Holme JA, Friede B, Gualtieri M, Kruszewski M, Schwarze PE, Skuland T, Refsnes M: Comparison of non-crystalline silica nanoparticles in IL-1 beta release from macrophages. Part Fibre Toxicol 2012, 9:32.

25. Winter M, Beer HD, Hornung V, Krämer U, Schins RPF, Förster I: Activation of the inflammasome by amorphous silica and $\mathrm{TiO}_{2}$ nanoparticles in murine dendritic cells. Nanotoxicology 2011, 5:326-340.

26. Zhang H, Dunphy DR, Jiang X, Meng H, Sun B, Tarn D, Xue M, Wang X, Lin S, Ji Z, Li R, Garcia FL, Yang J, Kirk ML, Xia T, Zink JI, Nel A, Brinker CJ: Processing pathway dependence of amorphous silica nanoparticle toxicity: colloidal vs pyrolytic. J Am Chem Soc 2012, 134:15790-15804.

27. Martinon F, Mayor A, Tschopp J: The inflammasomes: guardians of the body. Annu Rev Immunol 2009, 27:229-265.

28. Dinarello CA: Immunological and inflammatory functions of the interleukin-1 family. Annu Rev Immunol 2009, 27:519-550.

29. Stutz A, Golenbock DT, Latz E: Inflammasomes: too big to miss. J Clin Invest 2009, 119:3502-3511

30. Davis GS, Pfeiffer LM, Hemenway DR: Persistent overexpression of interleukin-1beta and tumor necrosis factor-alpha in murine silicosis. J Environ Pathol Toxicol Oncol 1998, 17:99-114.

31. Dowling JK, O'Neill LA: Biochemical regulation of the inflammasome. Crit Rev Biochem Mol Biol 2012, 47:424-443.

32. Haneklaus M, O'Neill LA, Coll RC: Modulatory mechanisms controlling the NLRP3 inflammasome in inflammation: recent developments. Curr Opin Immunol 2013, 25:40-45.

33. Latz E: The inflammasomes: mechanisms of activation and function. Curr Opin Immunol 2010, 22:28-33.

34. Zhou R, Yazdi AS, Menu P, Tschopp J: A role for mitochondria in NLRP3 inflammasome activation. Nature 2011, 469:221-225.

35. Thompson JK, Westbom CM, MacPherson MB, Mossman BT, Heintz NH, Spiess P, Shukla A: Asbestos modulates thioredoxin-thioredoxin interacting protein interaction to regulate inflammasome activation. Part Fibre Toxicol 2014, 11:24.

36. Morishige T, Yoshioka Y, Inakura H, Tanabe A, Yao X, Narimatsu S, Monobe Y, Imazawa T, Tsunoda S, Tsutsumi Y, Mukai Y, Okada N, Nakagawa S: The effect of surface modification of amorphous silica particles on NLRP3 inflammasome mediated IL-1 beta production, ROS production and endosomal rupture. Biomaterials 2010, 31:6833-6842.

37. Neumann S, Burkert K, Kemp R, Rades T, Dunbar PR, Hook S: Activation of the NLRP3 inflammasome is not a feature of all particulate vaccine adjuvants. Immunol Cell Biol 2014, 92:535-542.

38. Allison AC, Harington JS, Birbeck M: An examination of the cytotoxic effects of silica on macrophages. J Exp Med 1966, 124:141-154.

39. Nadler S, Goldfischer S: The intracellular release of lysosomal contents in macrophages that have ingested silica. J Histochem Cytochem 1970, 18:368-371.

40. Summerton J, Hoenig S: The mechanism of hemolysis by silica and its bearing on silicosis. Exp Mol Pathol 1977, 26:113-128.

41. Ghiazza M, Polimeni M, Fenoglio I, Gazzano E, Ghigo D, Fubini B: Does vitreous silica contradict the toxicity of the crystalline silica paradigm? Chem Res Toxicol 2010, 23:620-629. 
42. Iler RK: The Surface Chemistry of Silica. In The Chemistry of Silica: Solubility, Polymerization, Colloid and Surface Properties, and Biochemistry. New York: John Wiley \& Sons, Inc. 1979.p. 622-729.

43. Bolis V, Fubini B, Marchese L, Martra G, Costa D: Hydrophilic and hydrophobic sites on dehydrated crystalline and amorphous silicas. J Chem Soc Faraday Trans 1991, 87:497-505.

44. Fubini B, Bolis V, Cavenago A, Volante M: Physicochemical properties of crystalline silica dusts and their possible implication in various biological responses. Scand J Work Environ Health 1995, 21:9-14.

45. Gazzano E, Ghiazza M, Polimeni M, Bolis V, Fenoglio I, Attanasio A, Mazzucco G, Fubini B, Ghigo D: Physicochemical determinants in the cellular responses to nanostructured amorphous silicas. Toxicol Sci 2012, 128:158-170.

46. Johnston CJ, Driscoll KE, Finkelstein JN, Baggs R, O'Reilly MA, Carter J, Gelein R, Oberdörster G: Pulmonary chemokine and mutagenic responses in rats after subchronic inhalation of amorphous and crystalline silica. Toxicol Sci 2000, 56:405-413.

47. Ghiazza M, Tomatis M, Doublier S, Grendene F, Gazzano E, Ghigo D, Fubini B: Carbon in intimate contact with quartz reduces the biological activity of crystalline silica dusts. Chem Res Toxicol 2013, 26:46-54.

48. Wallingford WR, McCarty DJ: Differential membranolytic effects of microcrystalline sodium urate and calcium pyrophosphate dihydrate. J Exp Med 1971, 133:100-112.

49. Peeters PM, Eurlings IMJ, Perkins TN, Wouters EF, Schins RPF, Borm PJA, Drommer W, Reynaert NL, Albrecht C: Silica-induced NLRP3 inflammasome activation in vitro and in rat lungs. Part Fibre Toxicol 2014, 11:58.

50. Sager TM, Wolfarth MW, Andrew M, Hubbs A, Friend S, Chen TH, Porter DW, Wu N, Yang F, Hamilton RF, Holian A: Effect of multi-walled carbon nanotube surface modification on bioactivity in the C57BL/6 mouse model. Nanotoxicology 2014, 8:317-327.

51. Hamilton RF Jr, Xiang C, Li M, Ka I, Yang F, Ma D, Porter DW, Wu N, Holian A: Purification and sidewall functionalization of multiwalled carbon nanotubes and resulting bioactivity in two macrophage models. Inhal Toxicol 2013, 25:199-210.

52. Nash T, Allison AC, Harington JS: Physico-chemical properties of silica in relation to its toxicity. Nature 1966, 210:259-261.

53. Hemenway DR, Absher MP, Fubini B, Bolis V: What is the relationship between hemolytic potential and fibrogenicity of mineral dusts. Arch Environ Health 1993, 48:343-347.

54. Lison D, Thomassen LC, Rabolli V, Gonzalez L, Napierska D, Seo JW, Kirsch-Volders M, Hoet P, Kirschhock CE, Martens JA: Nominal and effective dosimetry of silica nanoparticles in cytotoxicity assays. Toxicol Sci 2008, 104:155-162.

\section{Submit your next manuscript to BioMed Central and take full advantage of:}

- Convenient online submission

- Thorough peer review

- No space constraints or color figure charges

- Immediate publication on acceptance

- Inclusion in PubMed, CAS, Scopus and Google Scholar

- Research which is freely available for redistribution 